\title{
REFLEXIONES PARA UNA DIDÁCTICA EMERGENTE DESDE LOS APORTES DE EDGAR MORIN
}

\author{
Vicente Eduardo Herrada* \\ Universidad Pedagógica Experimental Libertador, Venezuela \\ eduherr2006@hotmail.com
}

Recibido: 16/09/2019 Aceptado: 3/01/2020

\begin{abstract}
Resumen
La concepción tradicional de la didáctica tal como se ha venido entendiendo y aplicando en los últimos años, al parecer no cubre con las expectativas y las exigencias de la sociedad actual, lo cual ha generado cierta preocupación en la comunidad científica educativa. La necesidad de implementar una didáctica para la enseñanza de nuevos saberes y la formación del hombre del siglo XXI, ha sido motivo para que algunos investigadores de la educación se aboquen al estudio de este tema. En ese sentido, las ideas aportadas por el filósofo francés Edgar Morín en su obra "Los siete saberes necesarios para la educación del futuro", nos invitan a repensar la didáctica desde la complejidad. Por ello, el propósito fundamental del presente artículo de base documental, es hacer un análisis reflexivo sobre esta obra literaria, para plantear a partir de allí la necesidad de desarrollar una didáctica emergente que cumpla con los requerimientos para la formación del hombre nuevo y a su vez cubra con las expectativas que la educación del futuro demanda.
\end{abstract}

Palabras clave: Didáctica - Educación - Humanización - Complejidad.

\begin{abstract}
The concept of traditional didactics as it has been understood and applied during the past few years, does not appear to cover the requirements needed, as well as the expectations of current society, this has generated a certain degree of concern in the scientific education community. The need of implementing a didactic for the teaching of new knowledge and the development of the XXI century man has been the reason for some education researchers to work on the study of this matter. Regarding that, the ideas contributed by French philosopher Edgar Morin, in his work Seven complex lessons in education for the future, invite us to re-think the didactic from a complex angle. Therefore, the main purpose of this documental-based article is to carry out a reflective analysis of this literary work, and elaborate from it the necessity of developing an emerging didactic that meets the requirements for developing the new man, as well as covering the demands that the education of the future requires.
\end{abstract}

Keywords: Didactic - Education - Humanization - Complexity.

\footnotetext{
* Doctor en Educación; se desempeña como formador de profesores de Educación Musical en la Universidad Pedagógica Experimental Libertador UPEL-Maracay Venezuela donde es coordinador del Programa de Educación Musical. Director fundador de UPELJAZZ BAND, agrupación musical adscrita a la subdirección de extensión de la UPEL Maracay.
} 


\section{Introducción}

Las características de la sociedad actual signada por la tecnoglobalización y la pluralidad del conocimiento, colocan a la educación y a los educadores frente a un gran desafío como lo es encontrar nuevas fórmulas para organizar y dirigir los procesos educativos tendientes a la formación del nuevo ciudadano. Al parecer la concepción tradicional de la didáctica tal como se ha venido entendiendo y aplicando en los últimos años, no cubre con las expectativas y las exigencias de la sociedad de los nuevos tiempos, lo cual ha generado cierta preocupación en la comunidad científica educativa.

En ese afán por la búsqueda de soluciones a la problemática educativa mundial, el filósofo francés Edgar Morín (2000) propone en su obra "Los siete saberes para la educación del futuro", una serie de planteamientos que invitan a repensar la didáctica desde la complejidad, de tal modo que se logre a través de la renovación del pensamiento, la formación del ciudadano del siglo XXI.

Por ello, en el presente artículo se intenta hacer un análisis reflexivo sobre esta obra literaria para extraer de allí algunas ideas que pudiesen contribuir a la conformación de una didáctica emergente para la enseñanza de ciertos saberes que hasta ahora no han sido tomados en cuenta por las instituciones educativas.

En un primer momento se revisan las ideas de algunos autores pioneros en el estudio de las ciencias educativas y la pedagogía, como Herbart, Pestalozzi, Rousseau y Montessori, entre otros, con la finalidad de analizar la visión que estos pedagogos tradicionales tenían de la educación, y ver de qué manera estas primeras ideas han influido a través del tiempo en la enseñanza y en la generación de propuestas para la resolución de los problemas educativos, además se presenta en este apartado, la propuesta de Edgar Morín, la cual versa sobre los saberes que han de ser tomados en cuenta para la educación del futuro. De este modo, se describen de manera sucinta cada uno de los saberes propuestos por este autor a fin de extraer de allí elementos que puedan aportar ideas para la conformación de una didáctica emergente para la educación del futuro.

Luego se plantea el interrogante ¿hacia dónde va la didáctica? donde se analizan algunas definiciones las cuales fueron elaboradas durante las últimas cuatro décadas del siglo XXI por diversos autores, con el fin de develar el carácter asignado a esta disciplina desde diferentes perspectivas epistemológicas.

En base a los planteamientos desarrollados, se expone a continuación algunas razones para pensar en la necesidad de una didáctica emergente partiendo de las propuestas de Morin. Seguidamente, en las reflexiones finales se intenta sintetizar las ideas desarrolladas en el trabajo y presentar algunas observaciones y recomendaciones desde la visión particular del autor.

\section{La Didáctica: un camino andado, un camino por andar}

Desde que Juan Amós Comenius acuñara en el siglo XVII el término didáctica en su obra Didáctica Magna, esta disciplina científico pedagógica ha sido objeto de estudios e investigaciones basadas en diversas teorías y planteamientos, lo cual ha generado reacciones y controversias en cuanto a la comprensión y aplicación de los procedimientos inherentes al complejo arte de enseñar.

Es así como investigadores y estudiosos del tema posteriores a Comenius, fueron aportando ideas importantes para el desarrollo de la didáctica, tal es el caso de Herbart, quien abogó por el estudio de la pedagogía científica partiendo de elementos propios de la psicología donde el fin último de la educación debía ser el desarrollo de la personalidad de cada individuo.

Herbart cuestionaba la pedagogía como arte mecánico, pues ésta debía estar fundamentada tanto en lo científico, como en principios, entendía la educación como una necesidad para superar el estado natural del ser humano y la moral como el fin más elevado del hombre (Runge, 2009), en tal sentido, este teórico consideraba que los maestros deberían tener conciencia de la plasticidad humana (Mayer, 2000).

Por su parte Dewey, a través de sus teorías fundó las bases para la escuela nueva, donde se consideraba que los maestros debían incorporar las experiencias del aprendiz en los temas de estudio y que dichas materias de estudios no debían verse separadas o fuera del niño, sino como elementos que fluyen de una interacción conocimiento-sujeto cognoscente (Dorantes y Matus, 2007).

En cierto modo, Pestalozzi, Froebel, Montessori y el mismo Herbart refuerzan la tesis de Dewey, pues sus aportes introdujeron cambios en la idea que se tenía en ese entonces sobre las concepciones de maestro, enseñanza y método, para así dar forma a los principales fundamentos de la escuela moderna (Alves Duraes, 2010).

A partir de las propuestas de estos pedagogos, los cambios en el campo educativo y el de la pedagogía han marchado al ritmo de los acontecimientos mundiales que han impulsado las transformaciones en todos los ámbitos de la sociedad. De cualquier manera estos aportes han alimentado la discusión para la redimensionalización de la educación a través de la revisión de la pedagogía y la didáctica.

Esa necesidad de buscar soluciones a la problemática educativa ha sido una constante a lo largo de la historia, esto obedece quizás a la presión ocasionada por los acontecimientos ocurridos en el área social, política, económica y espiritual, los cuales se han sucedido de manera muy rápida, y en algunos casos de 
forma violenta, generando en consecuencia una vertiginosa alteración de la vida en todos los campos del orden mundial.

Una de las áreas del conocimiento que ha superado estas alteraciones asumiendo de manera responsable las consecuencias de los cambios, es el de las ciencias de la educación. Desde allí, y gracias al trabajo de científicos e investigadores, muchos han sido los esfuerzos por conocer cómo aprenden los individuos, qué requieren aprender y cuál es la mejor forma en que cada uno aprende; en ese sentido, se ha estudiado cada componente del proceso de aprendizaje como son el docente, el estudiante, el currículo y el contexto social en el cual se desarrolla el aprendizaje, afortunadamente todos han sido objeto de análisis y estudios, pues éstos siempre han sido considerados como los componentes esenciales y claves en el proceso de construcción del conocimiento para la formación del individuo.

La implementación de mecanismos que contribuyan a comprender el complejo mundo de la enseñanza ha representado una ardua tarea asumida por filósofos e investigadores, los cuales se han abocado al estudio de tan importante tema. El filósofo Edgar Morin por ejemplo, basa su obra en el principio de la complejidad para la comprensión de la condición humana, lo cual ha significado un gran aporte a la ciencia, la educación y a la humanidad en general.

Algunas de las ideas de este gran pensador francés están contenidas en "Los siete saberes necesarios para la educación del futuro", un trabajo que fue encargado por la UNESCO en 1999 al autor, a fin de que produjera un documento donde esbozara algunas ideas acerca de cómo debía ser la educación del futuro según la visión del eminente científico.

Aclara el autor que el texto no pretende ser un tratado de asignaturas que deben enseñarse en la escuela, tampoco es un compendio o una guía de enseñanza, se trata básicamente de exponer ideas para la resolución de problemas fundamentales del ámbito mundial y planetario, que requieren ser atendidos para su enseñanza en los próximos siglos, (Morín, López y Vallejo, 2000), es decir que más allá del cómo enseñar, el escritor hace referencia al qué enseñar.

Estas ideas deben ser consideradas por la educación en función de proponer una enseñanza basada en estos principios y crear estrategias dirigidas al cómo enseñar estos saberes para la formación del hombre y la construcción de la nueva sociedad.

A continuación se presenta un análisis de cada uno de los aspectos presentados por el autor a fin de extraer de allí los aportes más importantes que podrían contribuir a la renovación de la didáctica para la transformación de la educación.

\section{Los aportes de Edgar Morin: presente y futuro}

Edgar Morin es uno de los grandes pensadores del siglo XX e inicios del XXI, este sociólogo y filósofo francés se ha ocupado del estudio del mundo interno del individuo a través del abordaje de la investigación desde una perspectiva multidimensional de cara a la comprensión y formación del individuo sociológico.

La propuesta para la transformación de la humanidad a través del conocimiento del mundo interno del hombre, procura la renovación del pensamiento humano desde una visión profunda y compleja, así en la prolífica obra de este escritor, producto de muchos años de trabajo se ve reflejada su inquietud por el asunto de la enseñanza mediante la puesta en marcha de una urgente reforma del pensamiento.

Uno de los temas importantes planteados por el filósofo, se refiere a los siete saberes fundamentales que la educación de toda sociedad debe tratar. A decir del autor, los siete saberes parten de la idea de que existen siete vacíos profundos en las materias docentes, las cuales son ignoradas, ocultadas o desintegradas en fragmentos (Morín, López y Vallejo, 2000).

El primer vacío al cual el escritor hace referencia es al conocimiento y las implicaciones que conllevan al error y a la ilusión; la educación del futuro debe enfrentar la problemática de las cegueras del conocimiento, asunto éste que conlleva al problema del error y la ilusión, y es esto lo que se debe enseñar a todos los niños y a todos los ciudadanos, hacer frente a esta dificultad, pasa primeramente por reconocer las fuentes generadoras del error y la ilusión que no son otras que las fuentes psicológicas, culturales y biológicas (Morín, López y Vallejo, 2000).

Ciertamente la identificación de las fuentes generadoras de errores y su dominio permitiría una mayor fluidez del proceso de construcción del conocimiento, pues al suprimir los errores mentales, los intelectuales y los de la razón de la práctica de la enseñanza, se estaría atacando, y por ende eliminando las trabas que impiden el posicionamiento del conocimiento por parte del sujeto que aprende.

La negación del error ha sido quizás uno de los obstáculos que ha impedido la correcta apropiación del conocimiento, no existen sujetos, conceptos o teoría alguna que sean inmunes al error, pues la representación de la realidad se produce mediante un proceso perceptivo donde intervienen todos nuestros sentidos, incluso la misma percepción puede estar sujeta al error.

Las teorías y las aproximaciones conceptuales que pretendan revestirse de esa especie de inmunidad y se resistan a la posibilidad de ser refutadas corren el riesgo de convertirse sencillamente en aproximaciones teóricas carentes de toda robustez y confiabilidad (Popper, 1980). 
Efectivamente, el sistema de ideas construidas desde esa postura perfeccionista se arraiga en el espíritu del sujeto pensante de tal manera que reproduce otro sistema de creencias e ideas producto de los errores implícitos. Para eliminar el riesgo del error en el conocimiento hay que comenzar por reconocer el riesgo del error mismo; al respecto Morín (2000), afirma que "la educación debe dedicarse entonces a la identificación de los orígenes de errores, de ilusiones y de cegueras" (Morín, 2000, p.25).

Otro de los aspectos planteados por Morín es el que se refiere a la pertinencia del conocimiento, concebido como un conocimiento universal organizado y articulado en un sistema de información donde se deben insertar los problemas del mundo, los cuales deben ser tratados por la escuela en su contexto para que adquieran verdadero sentido, situarlos en un contexto amplio y complejo desde una visión global donde se integren las partes al todo y el todo a las partes.

El conocimiento pertinente debe reconocer las unidades complejas en sus múltiples dimensiones, así como la sociedad está conformada por una dimensión histórica, económica, social y espiritual, asimismo el hombre en sus múltiples dimensiones es una unidad biológica, social, síquica, afectiva y racional.

Evidentemente la escuela tradicional se ha centrado en el desarrollo de las capacidades y destrezas de los sujetos en formación, esto está muy bien, no obstante pienso que la manera de abordar el conocimiento de cara a esa formación no ha sido la más idónea puesto que en el proceso de enseñanza se ha tratado el conocimiento de forma parcelada y se ha descuidado la importancia que tienen las unidades complejas a las cuales se ha hecho referencia.

A propósito de la problemática del parcelamiento del conocimiento, el mismo se puede evidenciar en las instituciones educativas de todos los niveles, donde los contenidos son distribuidos por asignaturas pero sin que haya una relación entre ellas, pues cada materia se centra en los contenidos inherentes a su especialidad sin establecer nexos con las demás áreas del saber.

En ese sentido, para asumir la pertinencia del conocimiento es necesario que los encargados de coordinar y conducir los destinos de la educación de cada país, inicien una revisión de las estrategias de enseñanzas y ajustar los contenidos, de tal manera que éstos adquieran sentido para el estudiante y se logre una efectiva apropiación de los saberes, asimismo los educadores deberían propiciar en sus aulas de clases el desarrollo del conocimiento integrador, en el cual se profundice en las dimensiones del sujeto y del conocimiento, de tal modo que la unión entre la unidad y la multiplicidad formen un tejido complejo desde donde se asuma el conocimiento desde la interacción de los elementos multidimensionales que lo conforman.

Un aspecto relevante propuesto en la obra de Morin tiene que ver con la enseñanza de la condición humana, este es otro de los saberes necesarios que según el autor no se enseña en ninguna parte, por lo tanto la educación del futuro debe asumir el compromiso de llenar ese vacío, adoptando como principio fundamental: el significado del ser humano, reconociéndolo como ser integrante de una sociedad, de un mundo, de un universo, en fin de un cosmos.

Para enseñar la condición humana, asegura el autor, es necesario la alianza entre las diferentes ciencias; las ciencias de la tierra para ubicar al hombre en un espacio terrenal como ser en constante evolución, así como ubicar al planeta como parte de un universo; las ciencias de la vida que nos muestra el desarrollo de la humanidad; las ciencias humanas como la psicología, la sociología y la historia que dan cuenta del comportamiento humano y la evolución de las sociedades; la cosmología que explica sobre los orígenes del universo del cual forma parte el ser humano como un todo (Morín, 2000).

Efectivamente la separación de las ciencias ha permitido que el conocimiento se disperse y se construya en forma fragmentada, por ello es menester que las materias de estudio que se dicta en las instituciones se integren para lograr una verdadera enseñanza de la condición humana.

Para lograr este objetivo, la educación debe considerar el proceso de evolución del hombre desde su génesis hasta la actualidad, este sería el punto focal para la enseñanza de la humana condición, analizar el salto cualitativo y cuantitativo que ha experimentado el individuo en su evolución, para que sea reconocido como un ser inteligente, espiritual y universal tal como es su naturaleza misma, por lo tanto la enseñanza debe ocuparse por profundizar en el tema de la creación del mundo y del cosmos con sus miles de millones de galaxias y estrellas, además se debe trabajar por redefinir la concepción del nuevo hombre en su condición física como minúscula unidad viviente terrenal dentro de un sistema macrocósmico, considerar la dualidad del ser humano como ser cósmico y terrestre, este debe ser el norte de la nueva educación.

Desde hace unos cuatro siglos aproximadamente y muy especialmente a partir del siglo XX, la humanidad ha asistido a lo que Morin denomina la era planetaria, cuyo principal objetivo es educar para el despertar de la sociedad-mundo (Morín, 2006). Esta es una era caracterizada por la integración de todos los elementos que conforman el planeta mismo, de tal manera que el mundo se hace cada vez más un todo y el mundo como un todo está cada vez más en cada una de sus partes.

En esa dirección debe enfocarse la educación actual, orientar el proceso educativo hacia la comprensión de la historia y los hechos mundiales que han dado lugar a una nueva sociedad, a un nuevo orden planetario el cual debe ser comprendido por el sujeto en formación, de tal modo que este tenga una alta compresión sobre sus orígenes, que indague sobre su procedencia como ser cósmico y comprenda hacia dónde se dirige en su evolución, así, en la medida que esto se entienda, existirá un mejor sentido de pertenencia y una mayor conciencia planetaria por parte de los ciudadanos del mundo. 
De acuerdo con los planteamientos anteriores es necesario agregar que los pueblos y las naciones como entes organizados, y los sujetos como integrantes de estas organizaciones, no han evolucionado en solitario, por el contrario se han desarrollado en conjunción con un todo y en consecuencia el hombre como parte de una sociedad no puede desvincularse de ésta, por lo tanto, hombre-sociedad-mundo deben coexistir en estrecha relación en un escenario multidimensional donde se entreteje lo físico, biológico, psicológico y lo cultural, de donde emana todo el conocimiento que debe ser abordado por la escuela para su discusión, comprensión y aprehensión.

Por otra parte, es importante acotar que el desarrollo tecnológico y científico experimentado por la humanidad en los últimos años, ha permitido que la población tenga acceso a la información, haciendo posible que muchas personas de distintas regiones del mundo puedan enterarse de los acontecimientos mundiales y cósmicos casi de manera instantánea, lo cual ha abierto la brecha hacia la planetarización, de tal manera que la educación no puede estar de espaldas a esa realidad y por lo tanto las formas de abordar el conocimiento para la formación integral del ciudadano del planeta debe cubrir con las expectativas y las demandas que la era de la planetarizacion exige.

En función de estos argumentos es evidente que la educación actual requiere tomar nuevos rumbos, donde se erradique la práctica de la formación parcelada y desintegradora, y más bien se trabaje para que el propósito fundamental se centre en la consolidación de una educación que tome en cuenta al individuo desde una perspectiva holística, con una visión integradora y trascedente.

La planetarización es un concepto que la educación de este nuevo siglo debe enseñar si se quiere lograr un efecto unificador en la humanidad y asistir en el mediano plazo a la desaparición de todos aquellos agentes que amenazan con la destrucción del planeta ocasionadas por las ansias de poder y codicia de algunos grupos y naciones que han violentado todos los principios naturales, morales y espirituales con el fin de controlar el mundo.

Los cambios derivados de los acontecimientos mundiales ha llevado a Morín a plantear la necesidad de una educación para enseñar la identidad terrenal, es decir una enseñanza dirigida a concientizar al individuo sobre la importancia de asumir la ciudadanía terrestre como un derecho universal donde el mismo se ejerza a través de la práctica del sentido de pertenencia, del sentirse digno y orgulloso de ser ciudadano terrestre.

El ser humano es poseedor de un potencial creativo el cual debe poner al servicio de la causa por el rescate del planeta, si esto se lograra, señala Morin:

Entonces podemos avizorar para el tercer milenio la posibilidad de una nueva creación: la de una ciudadanía terrestre...la educación que es a la vez transmisión de lo viejo y apertura de la mente para acoger lo nuevo, está en el corazón de esta nueva misión (Morín, 2000, p.77).

Realmente el autor plasma en esta idea su firme creencia de que es a través de la educación que se podrá lograr la transformación de la especie humana, esto es ciertamente posible con la implementación de una educación orientada hacia ese objetivo, donde se aspire no sólo a la formación integral del individuo, como mucho se ha pregonado, sino más bien apostando a la salvación del planeta y por ende de la raza humana a través de la formación de la conciencia ciudadana, por lo tanto la educación del futuro deberá aprender una ética de la comprensión planetaria (Morin, 2000).

En otro apartado de su obra, el filosofo considera que la educación de los nuevos tiempos debe enfrentar las incertidumbres, por cuanto es este uno de los vacíos presentes en la enseñanza actual, quien no se ha ocupado en preparar al individuo para enfrentar sus propias incertidumbres y las del mundo en el que habita.

Efectivamente la escuela tiene los medios para enfrentar la incertidumbre mediante el aprendizaje de estrategias que ayuden a enfrentarla, pero no estrategias que supongan que el medio es estable, sino estrategias, como lo plantea Morín, que nos permitan ser capaces de afrontar lo inesperado a medida que se construyan nuevos conocimientos, por lo tanto enfrentar las incertidumbres constituye un punto capital de la enseñanza (Morin, 2000).

Si bien es cierto que no se puede predecir el futuro, también es cierto que se puede estar preparado para enfrentar las contingencias que se presenten; en ese sentido, los organismos e instituciones educativas deben planificar acciones a corto y mediano plazo donde se tracen líneas estratégicas orientadas a la solución de los problemas educativos. De esta manera, desde las escuelas, universidades y las demás instituciones involucradas en los asuntos educativos, se precisa hacer un frente para asumir la preparación del individuo para el futuro, una preparación basada en la realidad actual, pensando en las acciones del presente que conlleven a soluciones futuras.

Otro de los aspectos a desarrollar por la educación del futuro es el referido a la enseñanza de la comprensión, el cual parte de la idea del autor de la necesidad que tiene la educación de trabajar por una comprensión que se inserte "entre las personas como condición y garantía de la solidaridad intelectual y moral de la humanidad" (Morín, 2000, p.99).

Aunque la educación ha trabajado para la formación de los principios y los valores, el mundo ha estado signado por la falta de comprensión entre los seres humanos, así, en la familia, la sociedad, la escuela y en el 
mundo en general, se evidencia una alta influencia de incomprensión, donde la solidaridad, la tolerancia y la comprensión hacia el prójimo pareciesen haber caído en un profundo vacío de donde ha de ser rescatada.

En tal sentido la educación debe redoblar los esfuerzos para poner en práctica en las aulas y espacios educativos, el respeto y la aceptación del otro, respetando sus creencias, cultura, identidad, ideologías políticas y religiosas, sus discapacidades físicas e intelectuales, su condición de género, en fin la comprensión del ser humano como ser humano.

Morín trata en su obra acerca de la necesidad que existe de que la educación se enfoque en una enseñanza para la ética del género humano, en ese apartado se sintetiza, si se quiere, todo los aspectos anteriores, puesto que en una ética verdaderamente humana debe converger en una sola tríada, los términos individuo - sociedad - especie, de donde surja la conciencia y el espíritu propiamente humano, es decir, una ética de la conciencia de la concepción compleja del género humano, lo que el filósofo ha denominado una antropo-ética; entonces la antropo-ética debe conllevar la esperanza de lograr la humanidad como conciencia y ciudadanía planetaria.

Esto significa que el individuo y la sociedad deben interactuar en un bucle que permite la relación entre ambos, donde a través de la cooperación mutua se logre alcanzar el mayor estado de bienestar, es decir no existe sociedad sin individuo, ni individuo sin sociedad, uno es dependiente del otro, por ello la ética ciudadana y la ética de la especie humana son las dos vertientes en las cuales deben concentrarse las acciones para lograr que la humanidad se convierta en verdadera humanidad para que encuentre pacíficamente su realización dentro una gran confederación (Morin, 2000). Esta confederación debe constituirse desde la escuela, para así propiciar la participación e integración de los docentes, estudiantes, políticos, religiosos y todos los sectores que conforman la sociedad.

\section{¿Hacia dónde va la didáctica?}

En su evolución histórica, la educación ha estado sometida a fuertes cuestionamientos emanados de las críticas de los grandes científicos, investigadores y teóricos, quienes han discutido sobre sus posturas acerca de cómo debería conducirse el proceso de enseñanza aprendizaje.

De esta manera, la teoría rousseauniana estaba en contra de los métodos organizativos de la escuela y la falta de conexión entre el conocimiento y los estudiantes; Rousseau creía que el pilar fundamental de la escuela nueva estaba en proveer a los niños las opciones e instrumentos para que ellos por sí solos desarrollaran todas sus potencialidades (Maestre, 2009).

Por su parte, los marxistas y los anarquistas fijaban su posición en la defensa de un modelo ideal de sociedad a través de la transformación global del ser humano, en la cual jugaba un papel fundamental la educación. Más adelante, Habermas plantea su teoría de la acción comunicativa, donde explica que el aprendizaje comunicativo debe basarse en la creación de una comunidad de aprendizajes donde exista la interacción entre iguales, es decir una interacción de poder entre profesores y estudiantes (Maestre, 2000).

Como se puede apreciar, las opiniones acerca del tema de la educación tienen muchas aristas. En la actualidad las críticas provienen de diferentes fuentes, así desde el sector político opositor se habla de un sistema educativo fracasado; los expertos por su parte critican los enfoques, los procedimientos y los métodos empleados en el proceso de enseñanza; asimismo algunos estudiantes alegan que muchos docentes no están lo suficientemente preparados y actualizados para conducir y formar las nuevas generaciones, pues la ineficacia y la "falta de pedagogía" entorpece la labor educativa; de igual manera los profesores cuestionan a los estudiantes alegando que éstos no cuentan con los conocimientos previos básicos requeridos para asumir niveles más profundos de exigencias.

Esta posición de buscar responsables del deterioro de la calidad de la educación es una práctica muy común en nuestros días, pero pienso que más allá de eso es necesario que se entienda que todos somos parte del problema y por ende formamos parte de la solución, por lo tanto todos los involucrados en los asuntos educativos tenemos el compromiso de generar propuestas que enrumben al mundo por el camino de la transformación.

Las críticas que históricamente se le han hecho a la educación, involucra directamente a la didáctica, la cual ha transitado un sinuoso y largo camino, que gracias a la acción investigativa de los grandes pensadores ha logrado transformarse progresivamente y en cierta forma salvar los obstáculos para alcanzar un significativo perfeccionamiento en su aplicación, adaptándose a los diferentes contextos y a la dinámica de los distintos momentos históricos.

Para conectar con la idea anterior estimo necesario revisar cómo se ha manejado a través del tiempo el término didáctica comenzando por señalar que etimológicamente la palabra didáctica proviene de las expresiones griegas didaktiké, didaskein, didaskalia, las cuales tienen una relación común con el verbo instruir, enseñar, exponer con claridad. En su conceptualización más general algunas definiciones aluden al proceso de enseñanza, a los métodos y técnicas empleadas en dicho proceso, tal es el caso de la definición aportada por Herbart y sus discípulos en el siglo XIX, quienes la limitaban al conjunto de medios educativos e instructivos. Pero mucho más antes de Herbart, Comenius, uno de los teóricos antiguos más importantes de la 
pedagogía la asociaba con el arte al considerarla como un artificio universal mediante el cual se podía enseñar todas las cosas con eficacia, rapidez y alegría (Mallart, 2001).

En la actualidad el término didáctica es de uso universal y su conceptualización remite en unos casos a la ciencia y en otros a los medios instruccionales, así se evidencia en el cuadro siguiente donde presento algunas definiciones elaboradas durante las últimas cuatro décadas del siglo pasado aportadas por diferentes autores.

\section{Cuadro 1}

Análisis de la definición de didáctica

\begin{tabular}{|c|c|c|c|}
\hline Autor & Definición & Descriptores & Carácter \\
\hline $\begin{array}{c}\text { Buyse } \\
1964\end{array}$ & $\begin{array}{l}\text { Rama de la pedagogía, regula la práctica } \\
\text { docente. }\end{array}$ & Regula, controla & Normativo \\
\hline $\begin{array}{l}\text { Stocker } \\
1964\end{array}$ & $\begin{array}{l}\text { Trata los principios, fenómenos, formas } \\
\text { preceptos, leyes de toda enseñanza; es } \\
\text { por tanto una ciencia aplicada tendente a } \\
\text { la praxis. }\end{array}$ & $\begin{array}{l}\text { Ciencia } \\
\text { Praxis }\end{array}$ & Científico \\
\hline $\begin{array}{l}\text { Koop } \\
1967\end{array}$ & $\begin{array}{l}\text { Integración de dos tendencias: teoría del } \\
\text { método y del contenido de la enseñanza. }\end{array}$ & $\begin{array}{c}\text { Método } \\
\text { Enseñanza }\end{array}$ & Técnico \\
\hline $\begin{array}{l}\text { Villapando } \\
1970\end{array}$ & $\begin{array}{l}\text { Estudia los procederes para conducir al } \\
\text { educando y a la progresiva adquisición de } \\
\text { conocimientos. }\end{array}$ & Conocimientos & Analítico \\
\hline $\begin{array}{l}\text { Luis A. Matos } \\
1974\end{array}$ & $\begin{array}{l}\text { Disciplina pedagógica de carácter práctico- } \\
\text { normativo, tiene por objeto la técnica de } \\
\text { dirigir y orientar a los alumnos en su } \\
\text { aprendizaje. }\end{array}$ & $\begin{array}{l}\text { Dirigir } \\
\text { Conducir }\end{array}$ & Normativo \\
\hline $\begin{array}{l}\text { Rodríguez } \\
\text { Diéguez } \\
1974\end{array}$ & $\begin{array}{l}\text { Es la ciencia y la técnica de la variable } \\
\text { controladora del proceso educativo. }\end{array}$ & $\begin{array}{l}\text { Ciencia } \\
\text { Controla }\end{array}$ & $\begin{array}{c}\text { Normativo } \\
\text { Científico }\end{array}$ \\
\hline $\begin{array}{c}\text { Nerici } \\
1979\end{array}$ & $\begin{array}{l}\text { Conjunto de técnicas que reúne y } \\
\text { coordina, con sentido práctico, todas las } \\
\text { conclusiones y resultados que llegan de } \\
\text { las ciencias de la educación. }\end{array}$ & Coordina & $\begin{array}{l}\text { Normativo } \\
\text { Técnico }\end{array}$ \\
\hline $\begin{array}{c}\text { Gimeno } \\
1981\end{array}$ & $\begin{array}{l}\text { Teoría práctica de la enseñanza de } \\
\text { componente normativo que en forma de } \\
\text { saber tecnológico, organiza los medios } \\
\text { conocidos para guía la acción. }\end{array}$ & $\begin{array}{c}\text { Teoría } \\
\text { Organiza } \\
\text { Tecnológico }\end{array}$ & $\begin{array}{l}\text { Normativo } \\
\text { Técnico }\end{array}$ \\
\hline $\begin{array}{l}\text { Pérez Gómez } \\
1981\end{array}$ & $\begin{array}{l}\text { Ciencia y tecnología del sistema de } \\
\text { comunicación intencional donde se } \\
\text { desarrolla los proceso de enseñanza } \\
\text { aprendizaje. }\end{array}$ & $\begin{array}{c}\text { Ciencia } \\
\text { Tecnología }\end{array}$ & $\begin{array}{l}\text { Científico } \\
\text { Técnico }\end{array}$ \\
\hline $\begin{array}{c}\text { Arruda } \\
\text { Penteado } \\
1982\end{array}$ & $\begin{array}{l}\text { Conjunto de medios, técnicas } 0 \\
\text { procedimientos, que procuran guiar, } \\
\text { orientar, dirigir o instrumentalizar el } \\
\text { proceso de aprendizaje }\end{array}$ & $\begin{array}{l}\text { Medios técnicas, } \\
\text { guiar, orientar, } \\
\text { dirigir }\end{array}$ & $\begin{array}{l}\text { Normativo } \\
\text { Técnico }\end{array}$ \\
\hline $\begin{array}{l}\text { Pacios } \\
1982\end{array}$ & $\begin{array}{l}\text { La ciencia que estudia el proceso } \\
\text { instructivo en cuanto produce la formación } \\
\text { intelectual. }\end{array}$ & $\begin{array}{l}\text { Ciencia } \\
\text { Instrucción } \\
\text { Formación }\end{array}$ & Científico \\
\hline $\begin{array}{l}\text { Fernández } \\
\text { Huerta } \\
1985\end{array}$ & $\begin{array}{l}\text { Tiene por objeto las decisiones normativas } \\
\text { que llevan al aprendizaje. }\end{array}$ & $\begin{array}{l}\text { Decisiones } \\
\text { Aprendizaje }\end{array}$ & Normativo \\
\hline $\begin{array}{c}\text { Rosales } \\
1988\end{array}$ & $\begin{array}{l}\text { Es una ciencia de la educación que se } \\
\text { perfila como ciencia del proceso de } \\
\text { enseñanza-aprendizaje sistemática en } \\
\text { cuanto que optimizadora del aprendizaje }\end{array}$ & $\begin{array}{l}\text { Ciencia } \\
\text { Aprendizaje }\end{array}$ & Científico \\
\hline
\end{tabular}




\begin{tabular}{|c|c|c|c|}
\hline $\begin{array}{c}\text { Villar Angulo } \\
1990\end{array}$ & $\begin{array}{l}\text { Ciencia de la educación que explica y } \\
\text { estructura metódicamente el proceso } \\
\text { instructivo... y como consecuencia de su } \\
\text { proyección normativa y de carácter } \\
\text { tecnológico científico, estudia la } \\
\text { enseñanza desde el punto de vista de la } \\
\text { práctica escolar }\end{array}$ & $\begin{array}{l}\text { Ciencia } \\
\text { Instructivo } \\
\text { Tecnológico }\end{array}$ & $\begin{array}{l}\text { Científico } \\
\text { Normativo } \\
\text { Técnico }\end{array}$ \\
\hline $\begin{array}{c}\text { De la Torre } \\
1993\end{array}$ & $\begin{array}{l}\text { Es una disciplina reflexivo- aplicativa que } \\
\text { se ocupa de los procesos de formación y } \\
\text { desarrollo personal }\end{array}$ & $\begin{array}{l}\text { Disciplina } \\
\text { Formación }\end{array}$ & $\begin{array}{l}\text { Analítico } \\
\text { Práctico }\end{array}$ \\
\hline $\begin{array}{c}\mathrm{Pla} \\
1993\end{array}$ & $\begin{array}{l}\text { Es una disciplina posible que dirige el } \\
\text { campo semántico en el que se incardinan } \\
\text { curriculum e instrucción }\end{array}$ & $\begin{array}{l}\text { Disciplina } \\
\text { Dirige } \\
\text { Instrucción }\end{array}$ & Normativo \\
\hline $\begin{array}{c}\text { Oliva Gil } \\
1996\end{array}$ & $\begin{array}{l}\text { Es la ciencia y tecnología que estudia y } \\
\text { guía el proceso instructivo-educativo }\end{array}$ & $\begin{array}{l}\text { Ciencia } \\
\text { Tecnología } \\
\text { Guía } \\
\text { Instructivo }\end{array}$ & $\begin{array}{l}\text { Científico } \\
\text { Técnico } \\
\text { Normativo }\end{array}$ \\
\hline $\begin{array}{l}\text { Tejada } \\
\text { Fernández } \\
1999 \\
\end{array}$ & $\begin{array}{l}\text { Ciencia aplicada, tienen por objeto el } \\
\text { proceso de instrucción formativa integral e } \\
\text { integrada }\end{array}$ & $\begin{array}{l}\text { Ciencia } \\
\text { Instrucción }\end{array}$ & Científico \\
\hline $\begin{array}{c}\text { Percerisa } \\
1999\end{array}$ & $\begin{array}{l}\text { Disciplina científica que estudia los } \\
\text { proceso de enseñanza aprendizaje, se } \\
\text { producen en ambientes organizados de } \\
\text { relación comunicación intencional }\end{array}$ & $\begin{array}{l}\text { Disciplina } \\
\text { Enseñanza } \\
\text { aprendizaje }\end{array}$ & $\begin{array}{l}\text { Científico } \\
\text { Analítico }\end{array}$ \\
\hline
\end{tabular}

Fuente: Elaboración del autor con base en Sevillano (2005)

En el cuadro presentado se puede apreciar cómo el término didáctica ha motivado a diferentes interpretaciones en su conceptualización, de acuerdo a la visión de cada autor esta presenta caracterizaciones diferentes, sin embargo todas tienen un denominador común: refieren al proceso de aprendizaje, instrucción o formación del que aprende.

Una observación importante es que a las definiciones de la didáctica en su mayoría, se le ha asignado un carácter científico y tecnológico, pero con un componente normativo, donde la acción rectora y conductora del proceso de enseñanza aprendizaje es la tendencia dominante.

A pesar del carácter normativo, controlador y directriz que se le ha asignado a la didáctica, su advenimiento e integración a las ciencias de la educación sin duda ha contribuido en la organización del proceso de enseñar, tal es así que de las primeras concepciones prescriptivas conformada por el conjunto de recetas metódicas fundamentadas en rigurosos procedimientos científicos, se ha avanzado, sobre todo a partir del siglo XX, hacia la conformación de una didáctica cada vez más novedosa, apoyada por supuesto en las ideas, enfoques, recursos tecnológicos y demás elementos, los cuales han influido en el desarrollo progresivo de tan importante disciplina pedagógica.

No obstante, en la medida que el mundo cambia y las sociedades se transforman, se requiere procurar la reintegración del conocimiento, donde se unan todas las ciencias para la enseñanza de los saberes mediante técnicas de enseñanza que satisfagan las exigencias del mundo actual, esto es más o menos lo que expresa Morín en sus ideas, y hacia allá es que se debe encaminar la didáctica si se quiere cumplir con los objetivos.

\section{Necesidad de una didáctica emergente}

La didáctica encierra un complejo tratamiento cuyo objetivo principal es organizar el proceso de enseñanza de la manera más efectiva y eficaz, pero hay que considerar también que desde la teoría de la enseñanza se debe avanzar hacia el qué enseñar, este aspecto por lo general es ignorado por la didáctica tradicional, por lo tanto, es necesario rescatar estas ideas para la superación de esta limitante.

Al respecto Sevillano García (2005) expresa que la búsqueda de respuestas para reflexionar sobre formas de enseñar debe llevarnos a elaborar una nueva teoría de la enseñanza, pero para llegar a ello es necesario reflexionar sobre los nuevos escenarios mundiales y dar respuestas a interrogantes como:

¿Qué cambios están ocurriendo en el mundo en las organizaciones y en los servicios? ¿Qué cambios están ocurriendo en la economía? ¿Qué trasformaciones socioculturales están siendo apoyadas por las tecnologías de la información? ¿Hasta qué punto esas nuevas tecnologías podrán colaborar en la construcción de las estructuras cognitivas? en base a estos nuevos escenarios, ¿qué cambios en la enseñanza-aprendizaje están siendo requeridos? (Sevillano García, 2005, p.8). 
Estos y otros interrogantes ocupan la mente de algunos científicos, sociólogos, economistas y pedagogos del mundo quienes avizoran la necesidad de preparar a la humanidad para enfrentar esos cambios. Precisamente en el texto los siete saberes, Morín, en su planteamiento sobre los saberes que la escuela debe enseñar, remite al qué enseñar para lograr la humanización de la humanidad, pues en las instituciones educativas no se ha pensado en una didáctica para repensar y poner en marcha estas ideas. Por eso es necesario replantear la didáctica, implementar nuevos procedimientos y metodologías de enseñanza; y repensar la didáctica, según el filosofo, implica su adaptación a los requerimientos de la sociedad del siglo XXI, considerar las críticas y aprender de los errores del pasado, esto sería una decisión inteligente si se quiere avanzar hacia una nueva didáctica. La idea es poner en práctica estrategias, métodos y técnicas innovadoras que le den otro sentido al proceso de enseñanza, es decir, pensar en una formación útil y práctica, que en palabras de Simón Rodríguez (1988) significaría: educar para la vida.

En pleno siglo XXI, es necesario que la educación expanda sus aspiraciones hacia la conformación de una didáctica acorde con las exigencias del tercer milenio, donde las ideas de los grandes pensadores y científicos de la educación como en el caso de Morín, emerjan como modelos a seguir.

Ahora bien, pero, ¿qué, y para qué enseñar?

Morín lo plantea claramente: enseñar la moral, enseñar las luces del conocimiento, enseñar a conocerse así mismo, enseñar a enfrentar los problemas y a cómo resolverlos, enseñar la condición humana, esa es la misión, avanzar hacia una didáctica que combine el saber con el ser y promueva una enseñanza que garantice la recuperación de la salud del planeta y por ende, la continuidad en el tiempo de la raza humana (Morín, 2000).

A través de una didáctica pensada en estos términos se pueden crear vínculos que conecten la cultura científica con la cultura de las ciencias humanas, es una de las ideas centrales de los siete saberes necesarios de Morín. No obstante, para el logro de esta aspiración, es primordial tratar el tema de la condición humana, es decir, abordar el estudio del hombre y reconocerlo en toda su complejidad, saber de dónde viene y cuál es su rol como partícula viviente del cosmos, conocer su ubicación en el contexto del macro universo, de tal manera que el hombre dedicado al bien se alimente de la influencia de la cultura científica así como de la cultura de las ciencias humanas (Morín, López y Vallejo, 2000).

El científico francés propone una educación basada en la complejidad, la cual alude a lo que está tejido en conjunto (complexus), donde se entretejen los eventos, las acciones, interacciones, los azares, las incertidumbres, el caos, el desorden y todos aquellos elementos que constituyen el mundo de lo fenoménico (Morín, 1990). Una de las dificultades del pensamiento complejo, aclara el autor, es que "debe enfrentar lo entramado (el juego afinito de inter-retroacciones), la solidaridad de los fenómenos entre sí, la bruma, la incertidumbre, la contradicción" (Morín, 1990, p.33). Esto significa educar para un conocimiento que ponga orden en el caos y trabaje para la supremacía de la certidumbre sobre la incertidumbre, supondría la implementación de una didáctica de donde surjan alternativas para la solución del problema planetario y de la vida misma, a partir de la transformación de la conciencia humana, una didáctica que avance del pensamiento simple y reduccionista a un nuevo pensamiento basado en la complejidad, desde donde se procure la redimensión del conocimiento partiendo de la enseñanza de aquellos saberes que la educación tradicional ha ignorado hasta ahora.

A continuación se extraen algunas ideas de la obra "Los siete saberes necesarios para la educación del futuro", las cuales considero pueden aportar elementos para la construcción de una didáctica emergente necesaria para resolver los problemas educativos y lograr la formación de la sociedad-mundo que se quiere para esta humanidad, por lo tanto la nueva didáctica debe ocuparse de enseñar para:

- Que el individuo conozca cómo solventar los obstáculos epistemológicos, que aprenda nuevas formas de asumir el conocimiento que le permita construir el conocimiento a partir de sus experiencias y saberes, mundo, lo cual le proporcione alternativas para enfrentar los riesgos y las incertidumbres.

- Promocionar el abordaje de un conocimiento global, donde se vincule las partes con el todo y el todo con las partes a fin de aprehender la realidad en todas sus dimensión y complejidad.

- El conocimiento de la naturaleza humana como unidad compleja mediante la enseñanza multidisciplinaria, integrando los conocimientos de las ciencias naturales, las ciencias humanas, el arte, la literatura, la música y otras disciplinas que permitan indagar en la esencia de lo que es ser humano.

- La enseñanza de la historia de la era planetaria y para que el sujeto se reconozca como una entidad multidimensional, como un habitante mas de la tierra donde debe convivir en paz para garantizar su supervivencia así como la de toda la raza humana.

- Enfrentar las incertidumbres de los tiempos actuales, afrontar y modificar lo inesperado que surge de las nuevas informaciones. Para ello la didáctica tendría que considerar la 
importancia de los avances tecnológicos y las redes de información para implementarlos como recurso en el proceso de enseñanza.

- La promoción del diálogo entre semejantes y diferentes a fin de conocer y comprender las diversas culturas, aceptar al otro como hijo del universo con todas sus virtudes y sus limitaciones.

- Para la investigación y aprender investigando.

- Trabajar la ética del ser ciudadano como individuos que conforman una sociedad y profundizar en la idea de la ética del género humano.

En general lo que se requiere es la construcción de una nueva teoría de la enseñanza, que incluya técnicas y métodos de enseñanza dirigidas a la formación de la naturaleza humana, desarrollar en el estudiante la capacidad de reflexión que lo conduzca a aprender a conocer, a desaprender para aprender, aprender a pensar para que actúe con conciencia, una didáctica emergente que procure preparar al aprendiz para enfrentar los cambios que ocurren en el mundo y propicie la convivencia en una fraternidad, donde la solidaridad, el respeto, la honestidad y el amor por su patria, se constituyan en los pilares fundamentales de la sociedad-mundo del futuro.

\section{Reflexiones finales}

Luego de este escrito pienso que la educación ciertamente enfrenta uno de sus mayores retos, hacer frente a la realidad que caracteriza el hecho educativo del nuevo siglo. En ese sentido, la tecnoglobalización, las múltiples tendencias religiosas, la superpoblación, el convulsionado ambiente político, el problema ecológico y las nuevas formas de organización social, son sólo algunos de los temas que la educación debe abordar, pues éstos constituyen los elementos dominantes del estilo de vida actual, los cuales inciden directamente en la educación.

Todo este entramado de situaciones de orden espiritual, económica, política, ecológica y social debe ser considerada al momento de plantear una transformación de la didáctica, de tal manera que el conocimiento se construya y se reconstruya desde una perspectiva científica y compleja, tomando en cuenta la realidad que circunda al individuo y su mundo.

En la puesta en marcha de esta tarea, los docentes son pieza fundamental, por lo tanto éstos deben ejercer la ética como principio fundamental de su praxis, comprometerse con la misión para la cual se formaron y aportar ideas en su hacer pedagógico, en fin, creer, integrarse y reflexionar sobre el conocimiento que enseña, revisar los contenidos programáticos con el objeto de precisar su utilidad y pertinencia, incorporando los saberes populares y las experiencias propias de los aprendices a la cotidianidad del trabajo pedagógico, hacerse de técnicas y recursos apropiados para el desarrollo de los contenidos.

La inminente renovación de la didáctica es una tarea que debe comenzar por revisar los procedimientos metodológicos que históricamente se han utilizado en la enseñanza; pensar y repensar la didáctica desde la perspectiva de la complejidad y la multidisciplinariedad, fundamentada en las ideas, reflexiones y conceptualizaciones de grandes pensadores como Morin, significaría un salto significativo en la búsqueda de la optimización de la enseñanza.

Por lo tanto, desde la didáctica se debe avanzar hacia la indagación de nuevos métodos y formas de enseñar para estar a tono con los principios de la ley universal del cambio: si no reaccionas al cambio pereces, si reaccionas al cambio sobrevives, si anticipas el cambio adquieres una ventaja, si propicias el cambio te conviertes en líder.

\section{Referencias Bibliográficas}

Alves Duraes, S.J. (2010). Cultura y propagación de los Modelos de Maestro Entre Europa y Brasil: La Influencia de las Teorías Pedagógicas de Pestalozzi, Froebel y Herbart en la Segunda Mitad del Siglo XIX. Recuperado de http://www.congressods.com.br/segundo/images/trabalhos/docente/Sarah\%20Jane\%20Alves\%20Duraes.pdf.

Dorantes, C. y Matus, G. (2007). La Educación Nueva: La Postura de John Dewey. Recuperado de http://www.odiseo.com.mx/2007/07/print/dorantes-matus-dewey.pdf.

Maestre, A.B. (2009). Reflexión Sobre la Pedagogía Crítica. Innovación y Experiencias Educativas. Recuperado de http://www.csi-csif.es/andalucia/modules/mod_ense/revista/pdf/Numero_14/ANA\%20BELEN_MAESTRE_2.pdf

Mallart, J. (2001). Didáctica: Concepto, Objeto $\bar{y}$ Finalidad. Recuperado de http://www.xtec.cat/ tperulle/act0696/notesUned/tema1.pdf.

Mayer, F. (2000). Historia del Pensamiento Pedagógico. Recuperado de http://face.uasnet.mx/zona/mochis/recursosweb/alumnos/semestre/te.

Morín, E. (1990). Introducción al Pensamiento Complejo. Barcelona España: Gedisa Editorial.

Morín, E. (2000). Los Siete saberes Necesarios Para la Educación del Futuro. Caracas, Venezuela: Ediciones FACES/UCV.

Morín, E. López, G. y Vallejo, N. (2000). Reflexión Sobre los Siete Saberes Necesarios Para la Educación del Futuro. Recuperado de http://www.ispel3.edu.ar/_paginas/biblioteca/materiales/24.pdf. 
REVISTA DE LA ESCUELA DE CIENCIAS DE LA EdUCACIÓN, AÑo 16, NRO. 15, VOL. 2, JULIO A DICIEMRE DE 2020. PÁGINAS 23-33. ISSN 2362-3349 (EN LÍNEA). REFLEXIONES PARA UNA DIDÁCTICA EMERGENTE DESDE LOS APORTES DE EDGAR MORIN. VICENTE EDUARDO HERRADA.

Morín, E. (2006). Educar en la Era Planetaria. Barcelona España: Editorial Gedisa.

Popper, K. (1980). La Lógica de la Investigación Científica. Madrid. España: Editorial Tecnos.

Rodriguez, S. (1988). Inventamos o erramos. Caracas. Venezuela: Monte Ávida Editores.

Runge P, A. (2009). La Ética de Johann Friedrich Herbart como estética en sentido formativo o de cómo abrirle un espacio de posibilidad a la educación. En: Revista Educación y Pedagogía, 21(55), pp.55-74.

Sevillano G, M. L. (2005). Didáctica en el Siglo XXI. McGraw-Hill/interamericana de España, S.A.U. 